\title{
Effect of Methanol and Aqueous Extracts from Cinnamomum cassia (Cinnamon) Bark on Some Microbial Strains
}

\author{
H.Y. Vaghasiya*, R.L. Leva and R.M. Patel \\ Aspee Shakilam Biotechnology Institute, Navsari Agricultural University, \\ Surat, Gujarat, India \\ *Corresponding author
}

\section{A B S T R A C T}

Keywords

Antimicrobial,

Cinnamomum

cassia, Minimum

inhibitory

concentration

(MIC)

Article Info

Accepted:

12 October 2019

Available Online:

10 November 2019
The emergence and spread of antibiotic resistance, as well as the evolution of new strains of disease causing agents, are of great concern to the global health community. Commonly used medicinal plants of our community could be an excellent source of drugs to fight off this problem. This study is focused on exploring the antimicrobial property of Cinnamomum cassia (Cinnamon) bark extracts. Methanol and aqueous extract was used for this study. Extraction was done by cold percolation method. Antimicrobial activity was measured against four microbial strains: E. coli, B. subtilis, Enterobacter and $P$. chrysogenum. Extracts were diluted by serial dilution. Minimum inhibitory concentration (MIC) was measured by using spectrophotometer (OD at $600 \mathrm{~nm}$ ). Methanol extract had antimicrobial property against $B$. subtilis and Enterobacter; while aqueous extract was active against $E$. coli, B. subtilis and $P$. chrysogenum. The experiment confirmed the efficacy of Cinnamon extracts as natural antimicrobials and suggested the possibility of employing them in drugs for the treatment of infectious diseases caused by the test organisms.

\section{Introduction}

Antimicrobial resistance occurs when antibiotics are not effective against microorganisms. Microorganisms that develop antimicrobial resistance are sometimes referred to as "superbugs". As a result, the medicines become ineffective and infections persist in the body, increasing the risk of spread to others (Bashir et al., 2019). New resistance mechanisms are emerging and spreading globally, that results prolonged illness, disability, and death (Sekyere et al., 2018). Because of antimicrobial resistance, immune compromised diseases are spreading faster and also treatment is costly because of 
longer stay in hospitals (DeNegre et al., 2019). There is an argent need to find out alternative treatment with lower cost against resistant strains.

Medicinal plants have been known as important resources of natural antimicrobial compounds as an alternative that can potentially be effective in the treatment of these challenging bacterial infections (de Oliveira et al., 2019). Secondary metabolites of plants such as tannins, alkaloids, phenolic compounds, and flavonoids, are very useful source to treat many diseases (Mohotti et al., 2020).

Considering the vast potentiality of plants as sources for natural drug, this study aimed to investigate in vitro antimicrobial activity of extracts from Cinnamomum cassia (Cinnamon) bark against four microorganisms.

\section{Materials and Methods}

\section{Plant materials}

Plant dried Sticks were collected randomly from Surat, Gujarat, India. Plant dried sticks were washed in tap water, air dried and then homogenized to fine powder and stored in airtight bottles.

\section{Extraction}

Extraction of Cinnamomum cassia was done by cold percolation method (Vaghasiya and Chanda 2007; Chander et al., 2016). $10 \mathrm{~g}$ of air-dried powder was taken in $100 \mathrm{ml}$ of distilled water and $100 \mathrm{ml}$ methanol in a conical flask. The flask was boiled for $10 \mathrm{~min}$ and kept it for $24 \mathrm{~h}$ at room temperature in shaking condition. After $24 \mathrm{~h}$, extract solution was taken out in to glass petri plates (put the plates at room temp for air dry and allow it to completely dry). The dry extract was weighed and extractive yield was calculated by following formula.

Extractive yield $=($ weight of dry extract/ $10 \mathrm{~g})$ X 100

Extract was preserved in refrigerator until use.

\section{Microbial strains}

The standard microorganisms were used for antimicrobial study. The bacterial strains were grown in the nutrient broth and maintained on nutrient agar slants at $4^{\circ} \mathrm{C}$. The following bacterial strains were used for this study: Enterobacter aerogenes ATCC13048, E. coli ATCC25922, B. subtilis ATCC6633 and $P$. chrysogenum ATCC10108.

\section{Antimicrobial study}

Antimicrobial study was determined by broth dilution method. Microbial culture was inoculated in $\mathrm{N}$ broth and incubated for $12 \mathrm{~h}$ at $37^{\circ} \mathrm{C}$. Plant extract was dissolved in dimethyl sulphoxide and prepared it in six different concentrations $(5,2.5,1.25,0.625,0.312$, $0.156 \mathrm{mg} / \mathrm{ml}$ ). Dimethyl sulphoxide was used as control. Total seven tubes were prepared for each microbial strains per one plant extract. Tube 1 to 6 was used as test and tube 7 was used as control. $0.9 \mathrm{ml} \mathrm{N}$ broth was added in each test tube and $0.1 \mathrm{ml}$ extract was added at increasing concentration in each tube. All tubes were incubated overnight. Microbial growth was observed by using spectrophotometer (OD at $600 \mathrm{~nm}$ ).

\section{Results and Discussion}

Herbs and spices have been used since ancient times, because of their antimicrobial properties increasing the safety and shelf life of food products by acting against food borne pathogens and spoilage bacteria. C. cassia has a broad range of effects on different diseases 
like tumour, inflammation, diabetes, bacteria, virus etc (Lee et al., 2018; Wu et al., 2018; Zhang et al., 2019).

In the present study, Bark of Cinnamomum cassia (Cinnamon) was evaluated for its antimicrobial potential against four microorganisms in this study using micro broth dilution assay. Methanol and distilled water was used for extraction of the plant powder. Methanol extract gave the higher extractive yield $(5.35 \mathrm{~g} / 10 \mathrm{~g}$ powder $)$ than water extract $(2.69 \mathrm{~g} / 10 \mathrm{~g}$ powder). Graphs $1-6$ summarize the results obtained from this study. Graph 1 represents antimicrobial study of methanol extract of Cinnamomum cassia against $E$. coli. There was no antibacterial activity against $E$. coli while it showed antibacterial activity against $B$. subtilis with MIC value $1.25 \mathrm{mg} / \mathrm{ml}$ (Graph 2). Methanol extract also gave antibacterial potential against Enterobacter with the MIC value $2.5 \mathrm{mg} / \mathrm{ml}$
(Graph 3) but it was inactive against fungal strain $P$. chrysogenum (Graph 4). Aqueous extract of cinnamon was active against $E$. coli, $B$. subtilis and $P$. chrysogenum with the MIC values $5 \mathrm{mg} / \mathrm{ml}, 0.625 \mathrm{mg} / \mathrm{ml}$ and $1.25 \mathrm{mg} / \mathrm{ml}$ respectively (Graph 5, 6 and 8), while it was inactive against Enterobacter (Graph 7). As compared to methanol extract, water extract was more active against microorganisms especially against fungal strain.

Cinnamon can be suggested as an alternative to synthetic antibiotics, especially for the treatment of antibiotic-resistant bacterial infections. Cinnamon use in food products and cosmetics could be a good strategy to reduce or avoid bacterial degradation and thus to reduce the incidence of infection caused by food and cosmetics. However, there is a lack of clinical trials on the antibacterial effects of cinnamon, and therefore there is a need to be exploring its clinical efficacy (Fig. 1).

Fig.1

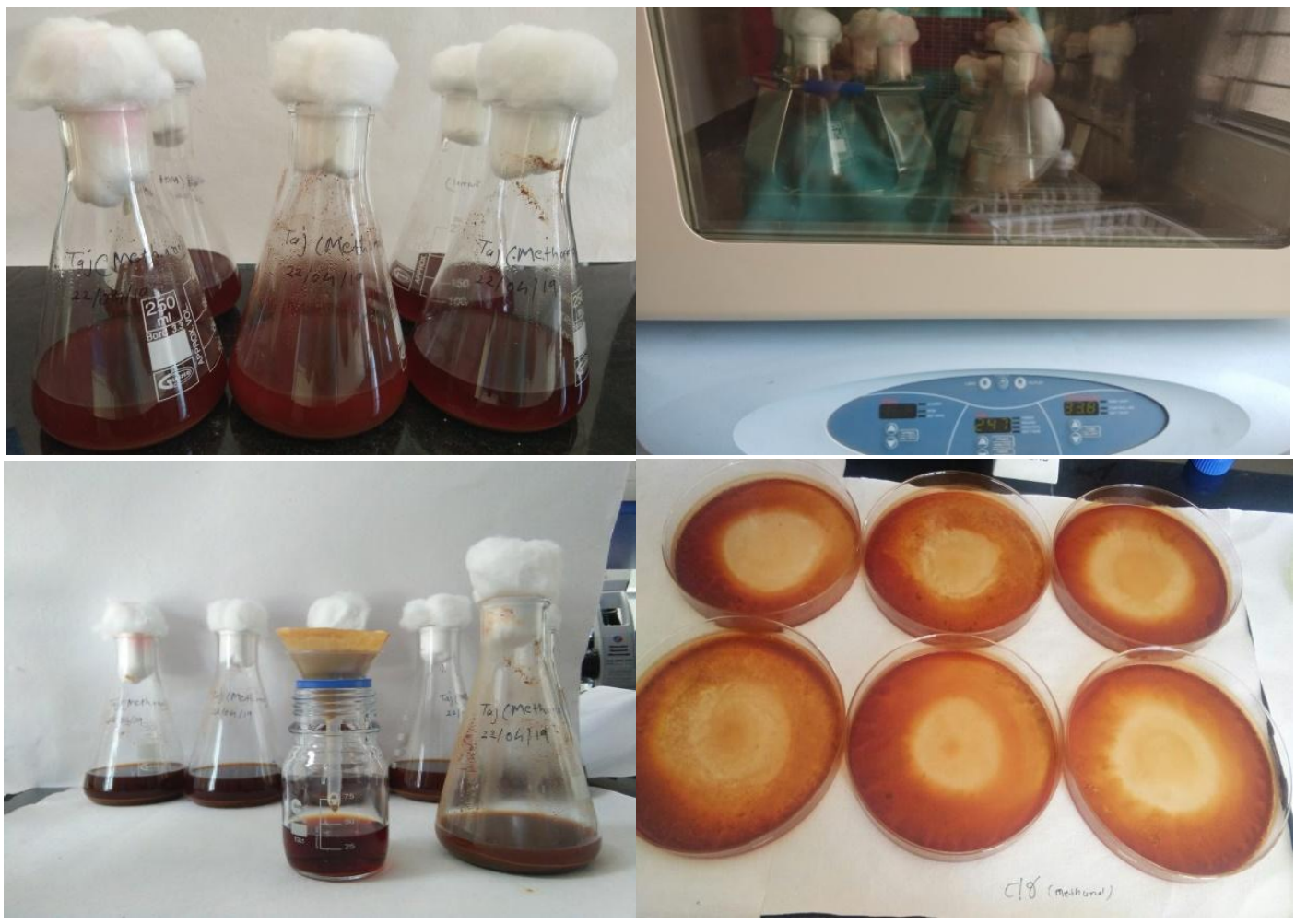



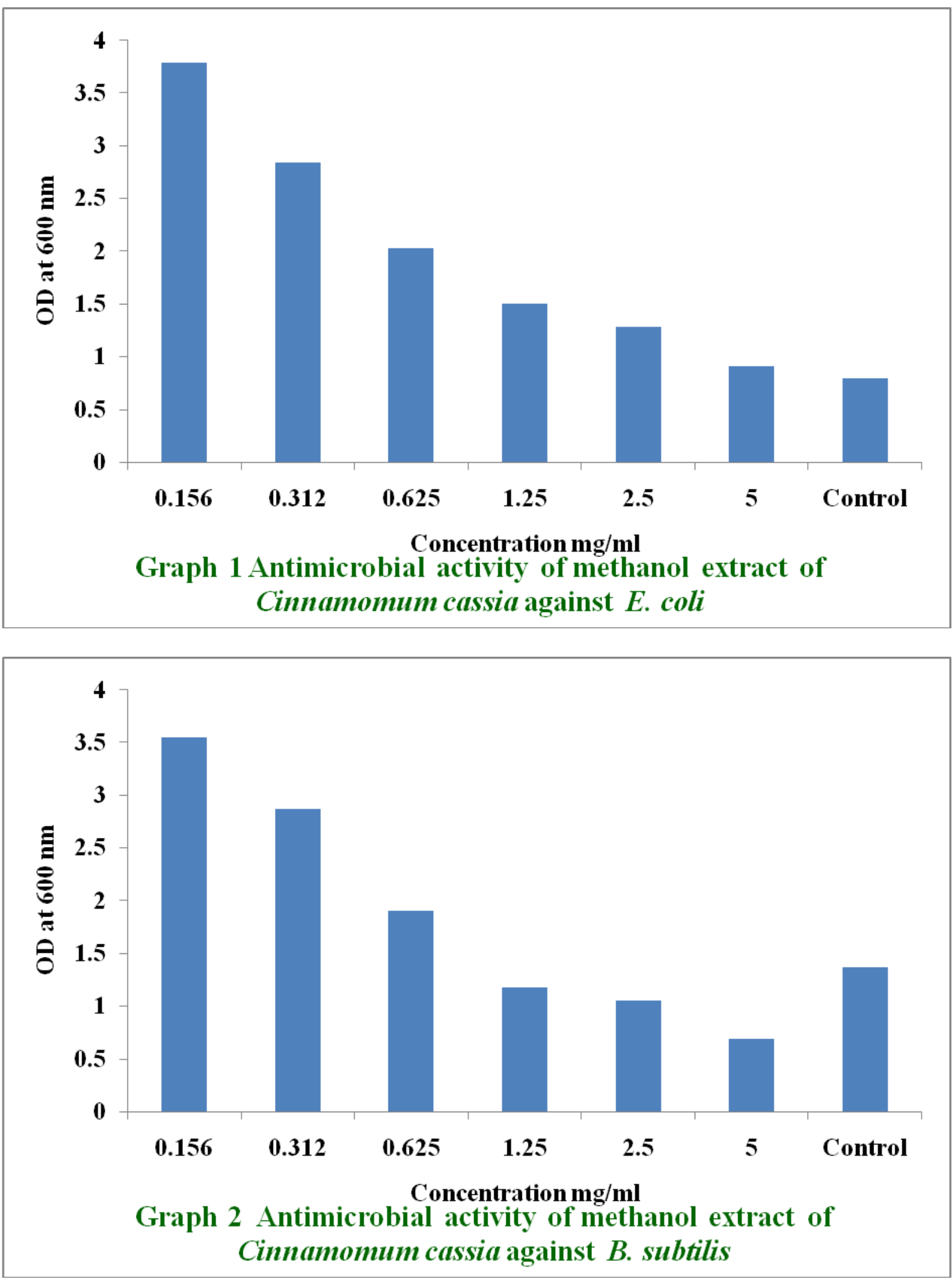

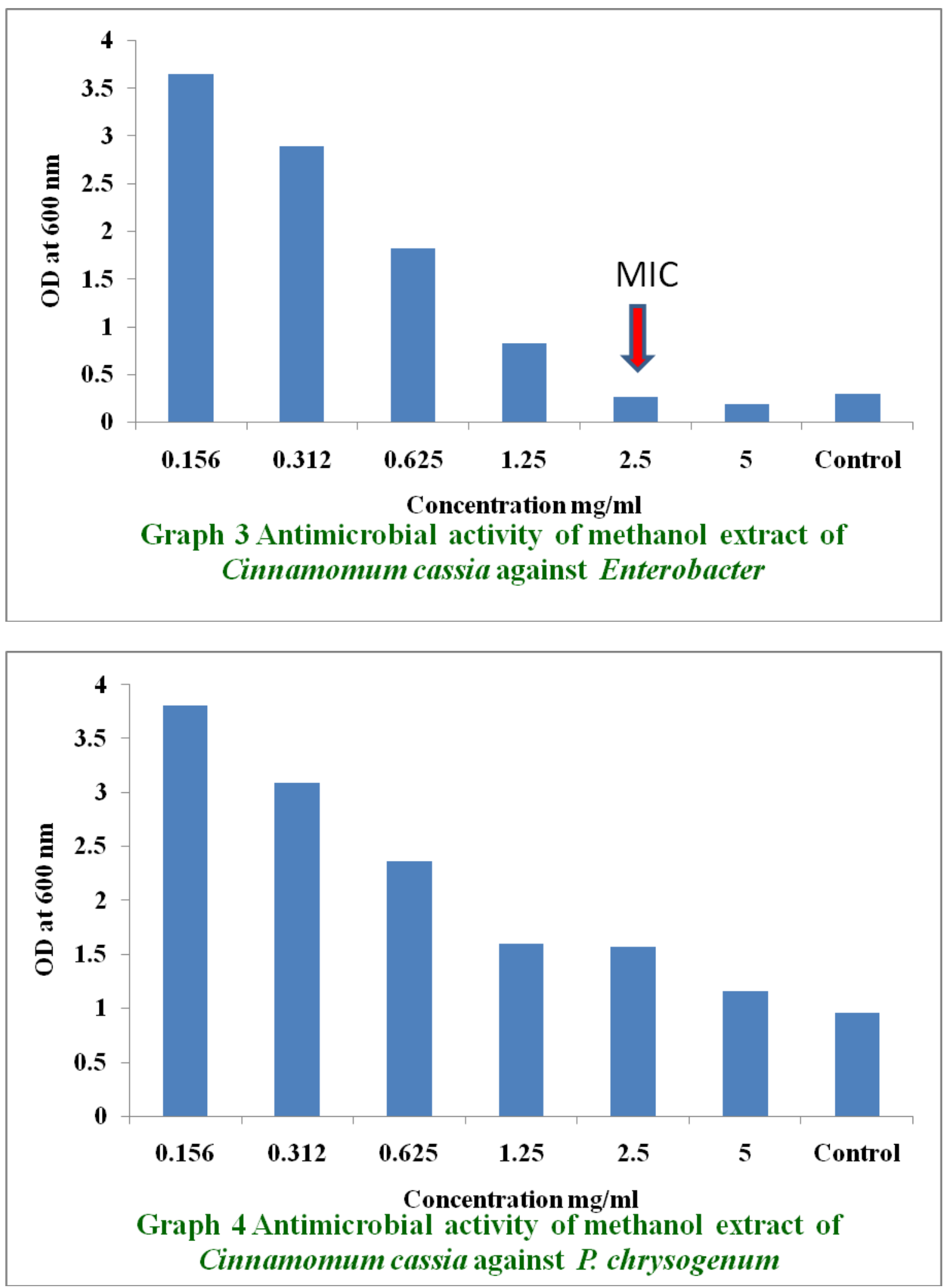

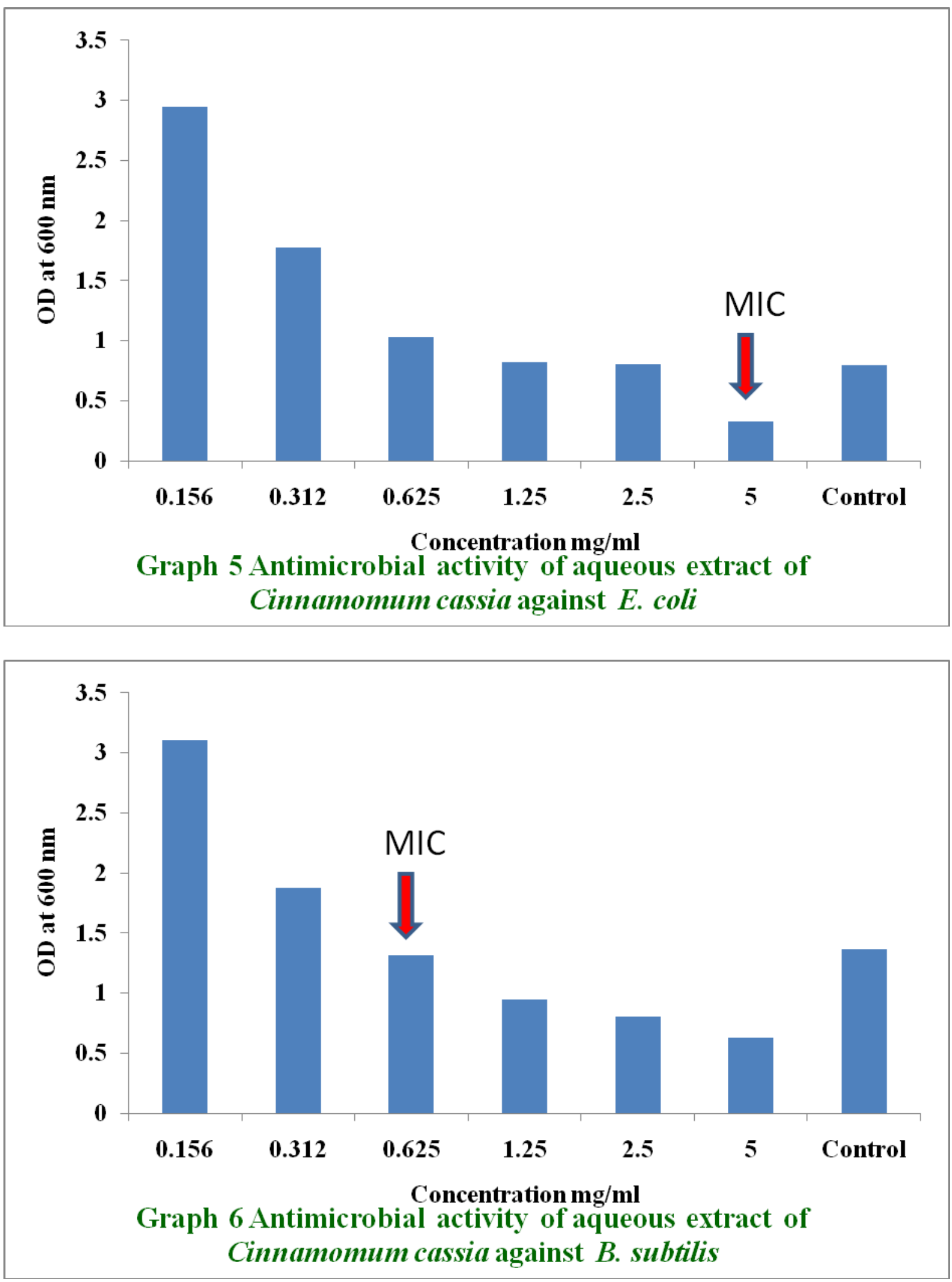

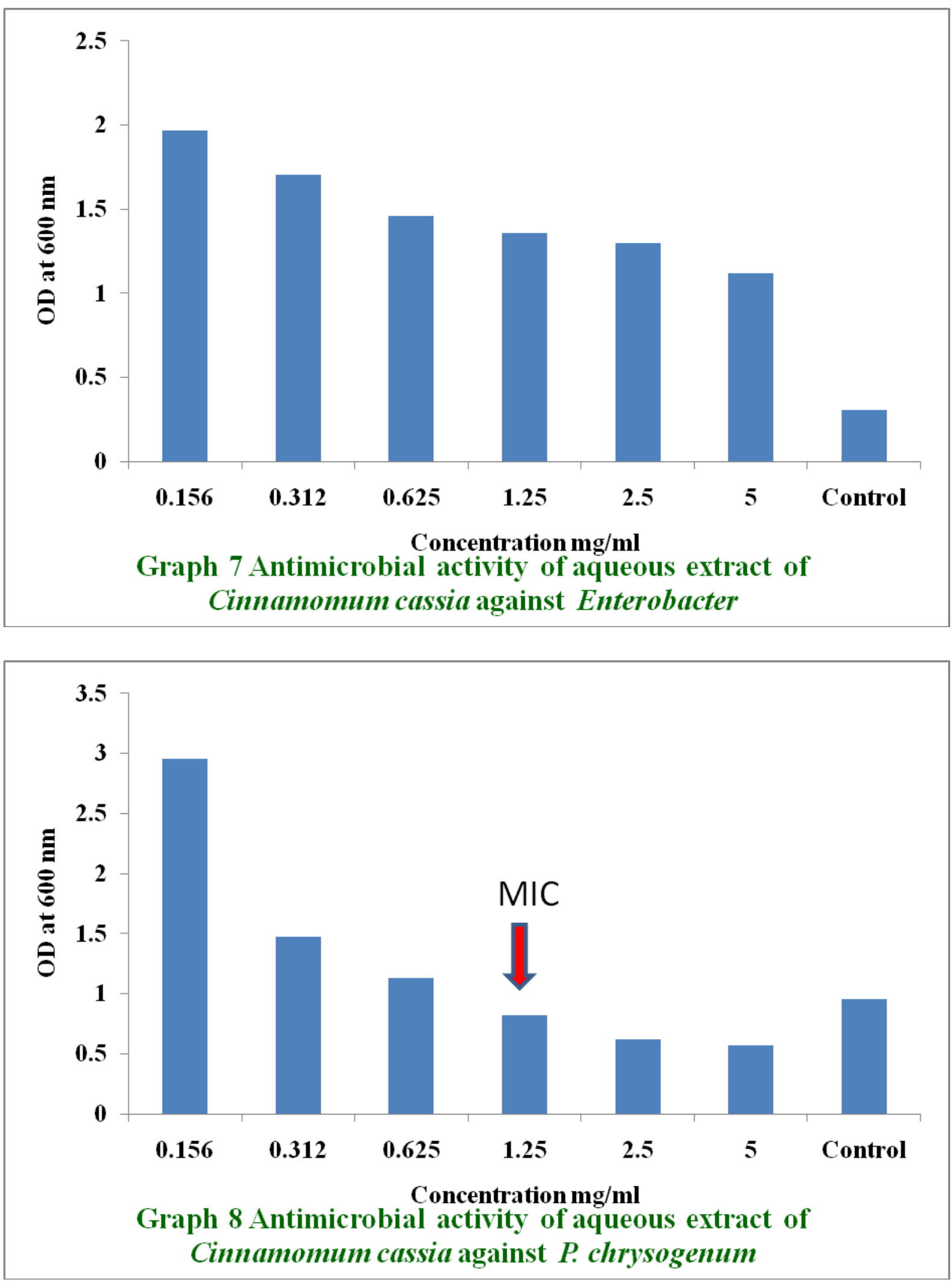


\section{References}

Bashir, A., I. Garba, A. A. Aliero, A. Kibiya, M. H. Abubakar, I. Ntulume, F. Sarkinfada, and A. Ezera. 2019. "Superbugs-related prolonged admissions in three tertiary hospitals, Kano State, Nigeria." Pan Afr Med J 32:166.

Chander, M. P., C. R. Pillai, I. P. Sunish, and P. Vijayachari. 2016. "Antimicrobial and antimalarial properties of medicinal plants used by the indigenous tribes of Andaman and Nicobar Islands, India." Microb Pathog 96:85-8.

de Oliveira, J. R., Pgdf Vilela, R. B. A. Almeida, F. E. de Oliveira, C. A. T. Carvalho, S. E. A. Camargo, A. O. C. Jorge, and L. D. de Oliveira. 2019. "Antimicrobial activity of noncytotoxic concentrations of Salvia officinalis extract against bacterial and fungal species from the oral cavity." Gen Dent 67(1):22-26.

DeNegre, A. A., M. L. Ndeffo Mbah, K. Myers, and N. H. Fefferman. 2019. "Emergence of antibiotic resistance in immunocompromised host populations: A case study of emerging antibiotic resistant tuberculosis in AIDS patients." PLoS One 14(2):e0212969.

Lee, E. J., T. W. Chung, J. H. Lee, B. S. Kim, E. Y. Kim, S. O. Lee, and K. T. Ha. 2018. "Water-extracted branch of Cinnamomum cassia promotes lung cancer cell apoptosis by inhibiting pyruvate dehydrogenase kinase activity." J Pharmacol Sci 138(2):14654.

Mohotti, S., S. Rajendran, T. Muhammad, A. A. Stromstedt, A. Adhikari, R. Burman, E. D. de Silva, U. Goransson, C. M. Hettiarachchi, and S. Gunasekera. 2020. "Screening for bioactive secondary metabolites in Sri Lankan medicinal plants by microfractionation and targeted isolation of antimicrobial flavonoids from Derris scandens." $J$ Ethnopharmacol 246:112158.

Sekyere, J. O., and J. Asante. 2018. "Emerging mechanisms of antimicrobial resistance in bacteria and fungi: advances in the era of genomics." Future Microbiol 13:24162.

Vaghasiya, Y. and Chanda, S. V. 2007 Screening of methanol and acetone extracts of fourteen Indian medicinal plants for antimicrobial activity. Turk J Biol 31:243-248.

Wu, H. C., C. T. Horng, Y. L. Lee, P. N. Chen, C. Y. Lin, C. Y. Liao, Y. S. Hsieh, and S. C. Chu. 2018. "Cinnamomum cassia Extracts Suppress Human Lung Cancer Cells Invasion by Reducing u-PA/MMP Expression through the FAK to ERK Pathways." Int J Med Sci 15(2):11523.

Zhang, C., L. Fan, S. Fan, J. Wang, T. Luo, Y. Tang, Z. Chen, and L. Yu. 2019. "Cinnamomum cassia Presl: A Review of Its Traditional Uses, Phytochemistry, Pharmacology and Toxicology." Molecules 24(19).

\section{How to cite this article:}

Vaghasiya, H.Y., R.L. Leva and Patel, R.M. 2019. Effect of Methanol and Aqueous Extracts from Cinnamomum cassia (Cinnamon) Bark on Some Microbial Strains. Int.J.Curr.Microbiol.App.Sci. 8(11): 1340-1347. doi: https://doi.org/10.20546/ijcmas.2019.811.157 